\title{
ON THE BACTERIOLOGY OF ASYLUM DYSENTERY.
}

\author{
By HAMilton TEBbUtT, B.A., M.B. (Sydney). \\ (From the Bacteriological Department, Lister Institute.)
}

THIS report contains the results of an investigation of the stools and blood sera of acute and relapsing cases of dysenteric diarrhoea in a large asylum in the Midlands.

In England Shiga's bacillus was isolated by Eyre (1904), from cases in Claybury Asylum. He found six cases out of nine infected with $B$. dysenteriae Shiga, and in some of these cases bacilli of the Flexner type were also present though the patients' sera agglutinated the former to a greater degree than the latter. Altogether Eyre found the Flexner type in 21 out of 44 cases of asylum dysentery so that even in 1904 this type predominated. As far as I can ascertain B. dysenteriae Shiga has not since with certainty been found either in Claybury, though investigated by Candler and Dean (1910), or in any other English Asylum.

McWeeney's bacillus isolated from an Irish Asylum in 1905 belongs to the mannite type though differing from Flexner's bacillus in not producing indol. (Probably identical with Bacillus " $Y$.")

The bacilli isolated by Aveline, Boycott and Macdonald in 1908 from an Asylum near Taunton were all of the mannite type and it is worth noting here that they all gave slight to considerable amounts of indol and the majority did not ferment maltose till late.

Macalister (1910) investigated the same Asylum with which the present report deals and found numerous bacilli of the mannite type, some fermenting sorbite, others not.

Contemporaneous with this work on Asylum dysentery is the work of Morgan on Infantile Diarrhoea (1906-1909). In a small number of 
cases of summer diarrhoea bacilli were found which resembled the mannite type but mainly on agglutination characters Morgan was dubious as to their admission to the Dysentery group. These bacilli fall into three sub-groups called by Morgan Nos. 3,4 and $4 a$ (see Table C). The non-motile mannite-fermenting bacilli which I have isolated from Asylum dysentery all belong to these three sub-groups and it seems highly probable that these are at least very closely related to those found in Infantile Diarrhoea, especially as Candler and Dean's strains from Claybury Asylum also correspond to Morgan's types No. 3 and No. 4 a (see Table C).

Asylums being almost the last stronghold of Dysentery in this country (excepting occasional sporadic cases (Marshall 1909) often of imported origin, and occasional small house epidemics) and those strains isolated of recent years being probably descendants of those which formerly caused so much more widespread epidemics, it seems somewhat unreasonable to regard a bacillus as a true Dysentery bacillus or not, according to whether it corresponds with a bacillus found in another part of the world, separated possibly from common ancestors by many generations subject to different climates and other factors which might lead to variations in character.

It has been shown that mannite-fermenting strains isolated from foreign sources differ considerably among themselves when thorough examination of their serological and biochemical properties is carried out (Morgan 1911), and in the case of British strains of the mannitefermenting group a similar lack of fixity of character is revealed. Unlike B. typhosus, which is an organism characterised by great stability of character irrespective of its place of origin, the mannite-fermenting $B$. dysenteriae would still appear to be undergoing evolutionary changes.

As to the methods used in this investigation it is only necessary to state that specimens of faeces were obtained as a rule through the post and plated out on MacConkey's lactose agar. A number of pale colonies were picked off into mannite peptone water. Tubes giving acid and gas were thrown out; those giving acid or no change were further examined. By this method the Gaertner group and lactose-fermenters were excluded, whilst Dysentery and Morgan's bacilli Nos. 1 to 5 (see Table C) were found if present. The patients' sera were examined if possible at the same time and at a later date, as agglutination was often found to increase after the early acute stage. The results of this part of the work are summarized in the following table (Table A). 


\section{TABLE A.}

\begin{tabular}{|c|c|c|c|}
\hline $\begin{array}{l}\text { Case } \\
\text { Number }\end{array}$ & Character of Faeces & $\begin{array}{c}\text { Agglutination } \\
\text { of Bac. Y by } \\
\text { patient's serum }\end{array}$ & $\begin{array}{c}\text { Non-lactose fermenters } \\
\text { not giving gas on Mannite }\end{array}$ \\
\hline 1 & - & $+1 / 50$ & $\begin{array}{l}\text { B. dysenteriae. Mannite type. } \\
\text { Non-sorbite group }\end{array}$ \\
\hline 2 & Soft yellow stool, no blood & $+1 / 100$ &, \\
\hline 3 & Dark green fluid, no blood & $+1 / 40$ &, \\
\hline 4 & $\begin{array}{l}\text { Yellow stool with blood } \\
\text { and mucus }\end{array}$ & - & ", \\
\hline 5 & $\begin{array}{l}\text { Greenish yellow fluid, no } \\
\text { blood }\end{array}$ & $+1 / 100$ & , \\
\hline 6 & Only blood and mucus ... & - & , \\
\hline 7 & Only blood and mucus ... & $+1 / 100$ & Sorbite group (also Morgan No. 1) \\
\hline 8 & Brown liquid, no blood ... & - & , \\
\hline 9 & Blood and mucus & $-1 / 50$ & Morgan No. $4 a$ \\
\hline 10 & Yellow-brown soft stool ... & $+1 / 200$ & Morgan No. 1 \\
\hline 11 & - & $+1 / 50$ & Morgan No. 1, No. 5 \\
\hline 12 & Blood and mucus & $+1 / 50$ & Morgan No. 1, No. $4 b$, No. 5 \\
\hline 13 & $\begin{array}{l}\text { Soft yellow stool with } \\
\text { mucus }\end{array}$ & $+1 / 100$ & Nil \\
\hline 14 & Soft clay coloured stool ... & $+1 / 100$ & Nil \\
\hline 15 & Soft brown stool & $+1 / 100$ & Morgan No. $4 b$ \\
\hline 16 & Green fluid with mucus & $+1 / 50$ & Morgan No. 1 \\
\hline 17 & Green fluid & $+1 / 50$ & Morgan No. 1 \\
\hline 18 & Soft brown stool & $+1 / 100$ & B. proteus \\
\hline 19 & Brown fluid & - & Morgan No. 1 or No. 2 \\
\hline 20 & Greenish fluid & $+1 / 100$ & Morgan No. 5 \\
\hline 21 & Green fluid & $+1 / 200$ & Nil \\
\hline
\end{tabular}

TABLE B.

\begin{tabular}{|c|c|c|c|c|c|c|c|c|c|c|c|}
\hline & \multirow[b]{2}{*}{ Strain } & \multicolumn{8}{|c|}{ Dilutions of " $\mathrm{Y}$ " serum } & \multirow{2}{*}{$\begin{array}{l}\text { Bac. } \\
\text { emulsion } \\
\text { +saline }\end{array}$} & \multirow{2}{*}{$\begin{array}{l}\text { Normal } \\
\text { serum } \\
1 \text { in } 60\end{array}$} \\
\hline & & 125 & 250 & 500 & 1000 & 2000 & 4000 & 8000 & 16000 & & \\
\hline & Bac. Y & + & + & + & + & + & + & - & - & -. & - \\
\hline & B.Flexner & + & + & + & + & + & + & - & - & - & - \\
\hline & Case 1 & + & + & + & + & + & + & - & - & - & - \\
\hline & Case 2 & + & + & + & + & + & $\stackrel{+}{+}$ incompl. & - & - & - & trace \\
\hline & Case 3 & + & + & + & + & + & $\stackrel{+}{+} \underset{\text { incompl. }}{ }$ & - & - & - & - \\
\hline & Case 4 & + & + & + & + & + & - & - & - & - & - \\
\hline & Case 5 & + & + & + & + & + & $\stackrel{+}{+}$ incompl. & - & - & - & - \\
\hline & Case 6 & + & + & + & + & + & - & - & - & - & - \\
\hline & Case 7 & + & + & + & + & + & - & - & - & - & $-\cdot$ \\
\hline & Case 8 & + & + & + & + & + & - & - & - & - & - \\
\hline
\end{tabular}

Not included in this table are seven other cases, from whom serum was not obtained, but the stools, usually consisting of a greenish fluid, were examined and no non-lactose fermenters found. 
In a further series of ten cases whose stools were not examined the sera agglutinated Bacillus " $Y$ " in dilutions varying from 1-120 to 1-200.

Summarizing, out of 28 cases whose stools were examined, eight cases were found to be excreting Dysentery bacilli, which were not found necessarily associated with blood and mucus. In one case passing blood and mucus, all the non-lactose fermenting bacilli found showed identical characters and corresponded with Morgan's No. 4 a (apparently with some affinities to the Dysentery group) which was also found twice in Claybury by Candler and Dean. The other most common non-lactose fermenters found were the $N_{0} .1$, in seven cases, $N_{0} .5$ in three cases, and No. $4 \mathrm{~b}$, resembling Ledingham's Bacillus $A$ of flies, in two cases. Many of these associated bacilli were tested with the patient's serum from whom they were isolated and in no case was any agglutination observed though positive with Bacillus " $Y$ " in each case.

\section{Classification of the Dysentery bacilli isolated from this epidemic.}

In connection with the mannite group the relations of the strains from different sources one to another have not yet been satisfactorily elucidated. In an examination of many strains both English and foreign, Morgan found that agglutination and absorption methods did not result in the same grouping as did the use of the Biochemical method. However, I am only concerned with Asylum dysentery in this country and here it does seem possible to divide the strains found into two groups, the sorbite-fermenters and the non-sorbite-fermenters, corresponding in the main with Morgan's bacilli No. 3 and No. 4. As to whether the latter, isolated from summer diarrhoea, are Dysentery bacilli, it is scarcely possible at this date to make a definite statement.

The limits of macroscopic agglutination by a " $Y$ " serum of the eight strains from this epidemic were determined, and as is shown in the table there is no great variation, most of the strains being agglutinated to the same titre as Bacillus $Y$ and B. Flexner.

Fermentation tests (see Table $\mathrm{C}$ ), however, bring out a number of variations. Their action is uniform on glucose, mannite, dulcite, lactose, saccharose, inulin and adonite peptone water, and they are all non-motile, non-liquefying bacilli. Great variability is found, however, on maltose, dextrin, arabinose, raffinose and sorbite. On the whole their facility to ferment maltose and dextrin is, if present, slight and delayed, more 
general and rapid in the case of arabinose and raffinose. In sorbite, however, we have a reagent which permits a classification of these strains. Strains 7 and 8 give acid production in sorbite-peptone water in 24 hours whilst the remaining six do not, even after 14 days. It appears to be a very constant character. Three colonies each of two of the non-sorbite fermenters have been growing in sorbite-peptone water for six months with sub-cultures every three to four weeks, and manifest no apparent tendency to acquire the sorbite-fermenting character. So far attempts to get this variation from papillae on sorbite-agar have not been successful.

TABLE C.

\begin{tabular}{|c|c|c|c|c|c|c|c|c|c|c|c|c|c|c|c|c|c|}
\hline Orgar & nism & 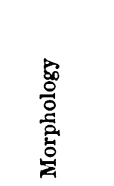 & $\begin{array}{l}\text { 递 } \\
\text { 产 }\end{array}$ & 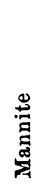 & 泀 & 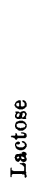 & 离 & 2 & 15dys. & : & 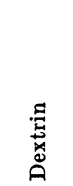 & 鸪 & 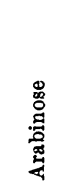 & 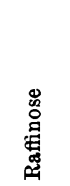 & 惫 & 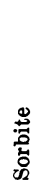 & 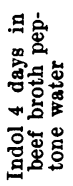 \\
\hline $\begin{array}{l}\text { B. Dyse } \\
\text { (Flexne }\end{array}$ & $\begin{array}{l}\text { enteriae } \\
\text { er) }\end{array}$ & N.M.B. & A & A & - & - & & A & alk & A & A & - & A & A & - & - & \\
\hline $\begin{array}{l}\text { Bac. Y (H } \\
\text { Russell }\end{array}$ & $\begin{array}{l}\text { Hissand } \\
\text { l) }\end{array}$ & N.M.B. & A & $\mathbf{A}$ & - & - & & A & alk & A & latea & - & - & $\mathbf{a}$ & - & - & \\
\hline Case 1 & $\ldots$ & N.M.B. & A & A & - & - & - & A & alk & latea & - & - & late a & a & - & - & \\
\hline,, 2 & $\ldots$ & N.M.B. & A & A & - & - & - & A & alk & - & late a & - & A & latea & - & - & \\
\hline, 3 & $\ldots$ & N.M.B. & A & A & - & - & - & A & alk & late a & - & - & A & A & - & - & \\
\hline,$\quad 4$ & $\ldots$ & N.M.B. & A & A & - & & - & A & alk & - & - & - & $\stackrel{-}{\text { late }} \mathbf{a}$ & A & - & - & \\
\hline,, 5 & $\ldots$ & N.M.B. & A & A & - & - & & 0 & alk & - & - & - & latea & $\overline{\text { latea }}$ & - & - & \\
\hline,$\quad 6$ & $\ldots$ & N.M.B. & A & A & - & - & & A & alk & latea & - & - & - & latea & - & - & \\
\hline,, 7 & $\ldots$ & N.M.B. & A & A & - & - & - & A & alk & latea & - & - & A & - & - & A & \\
\hline,, 8 & $\ldots$ & N.M.B. & A & $\mathbf{A}$ & - & - & - & 0 to $\mathrm{a}$ & alk & - & - & - & - & - & - & $\mathbf{A}$ & + \\
\hline,,$\quad 9$ & $\ldots$ & N.M.B. & A & A & - & - & - & A & $\mathrm{ACl}$ & A & $\mathrm{a}$ & - & A & $\overline{\text { latea }}$ & - & - & \\
\hline Morgan & No. 1 & M.B. & $A G$ & - & - & - & 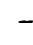 & 0 & alk & - & - & - & - & - & - & $-\cdot$ & + \\
\hline " & No. 3 & N.M.B. & A & $\mathbf{A}$ & - & - & - & A & 0 & $\mathbf{A}$ & $\mathbf{A}$ & - & A & - & $\ldots$ & $\mathbf{A}$ & + \\
\hline ", & No. 4 & N.M.B. & A & $\mathbf{A}$ & - & - & & A & alk & - & - & - & A & a & $\ldots$ & - & - \\
\hline$"$ & No. $4 \mathrm{~A}$ & N.M.B. & A & A & - & - & - & A & $\mathrm{ACl}$ & $\ldots$ & $\ldots$ & $\ldots$ & $\ldots$ & $\ldots$ & $\ldots$ & - & - \\
\hline , & No. 4 B & M.B. & $\mathbf{A}$ & $\mathbf{A}$ & - & - & - & A & Alk & $\ldots$ & $\ldots$ & $\ldots$ & $\ldots$ & $\ldots$ & $\ldots$ & - & + \\
\hline$"$ & No. 5 & M.B. & A & - & - & - & - & 0 & alk & $\ldots$ & $\ldots$ & $\ldots$ & $\ldots$ & $\ldots$ & $\ldots$ & - & \\
\hline
\end{tabular}

N.M.B. $=$ Non Motile Bacillus. M.B. $=$ Motile Bacillus. $\quad \mathbf{A}=\mathrm{Acid}, \mathrm{a}=$ slight acidity, $\mathrm{Alk}=$ Alkaline, alk=slight alkalinity. $\mathrm{ACl}=$ acid and clot. $\mathrm{AG}=$ acid and gas. 
Association of indol production with fermentation of sorbite.

The rapid production of indol in peptone beef broth co-exists with the facility to ferment sorbite, as was noted by Morgan with other strains.

The accompanying table (Table D) shows that the two sorbitefermenters form indol within two days, becoming very marked by the sixth day and persisting till at least the eighteenth day. The nonsorbite fermenters do not give indol in broth in six days, but with one

TABLE D.

Formation of Indol.

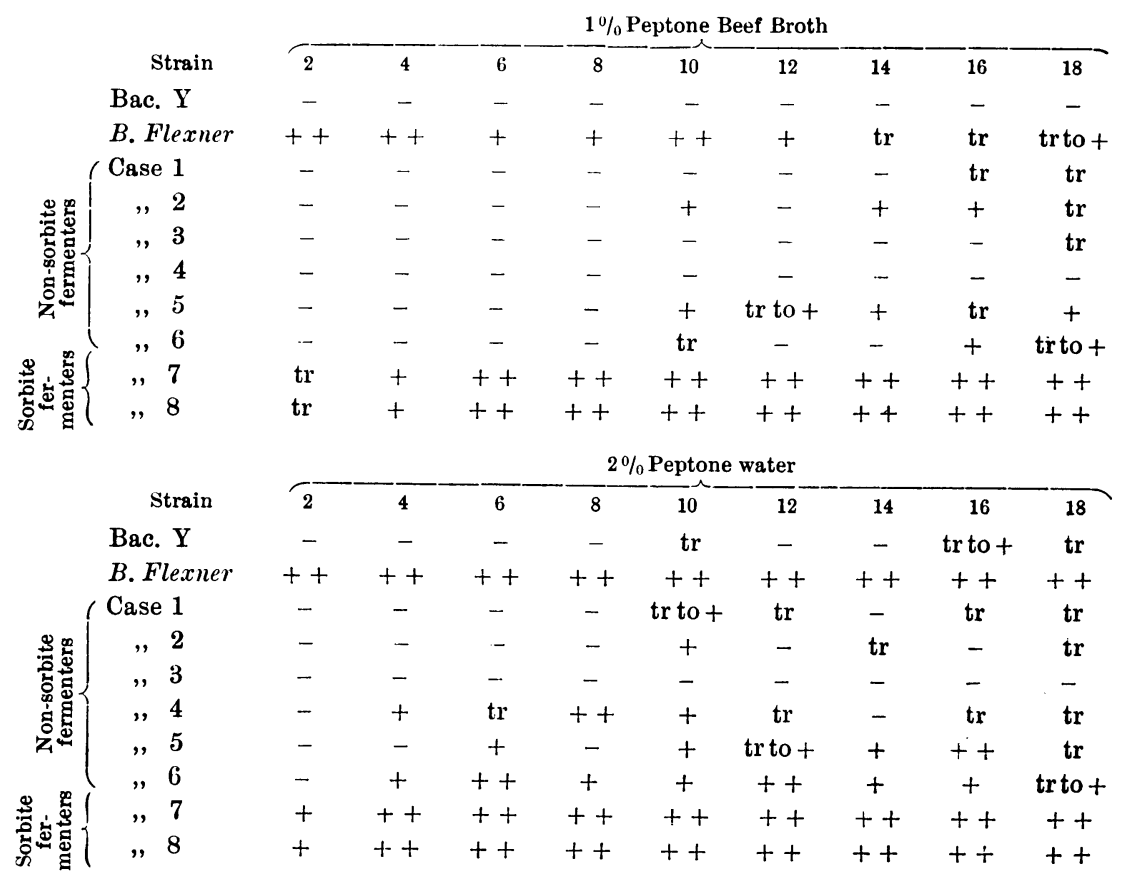

exception all these gave varying amounts, usually small, at a later date between the eighth and eighteenth day. The contrast is very striking. As a general rule more indol is detected in $2 \%$ peptone water than in broth (bullock's heart) and it is certainly detected earlier. The paradimethyl-amido benzaldehyde test for indol was invariably employed.

With regard to other strains recently isolated in this country, those obtained by Candler and Dean from Claybury fall naturally into the 
sorbite-fermenting group, and those isolated by Bainbridge and Dudfield from a small house epidemic in London are described also as having fermented sorbite.

The bacillus found in case 9 is an interesting one, as a similar organism was found at Claybury Asylum in two cases and also by Morgan in summer diarrhoea. It tends to agglutinate spontaneously but after getting over this difficulty more or less, it agglutinated up to 1 in 200 with " $Y$ " serum, not at all with normal serum. It is easily trained to ferment lactose, but will not ferment sorbite and does not produce a trace of indol even after 18 days in $2 \%$ peptone water. Its relation to dysentery is not established but it is somewhat suggestive that it was the only non-lactose fermenter found in a stool consisting of blood and mucus.

\section{Examination of fies.}

This epidemic was at its height in the late summer and early autumn when house flies had already begun to diminish in number. However not much difficulty was experienced in catching flies from the infected wards and adjacent rooms. Batches of 10 to 40 flies from different wards were placed in sterile tubes and conveyed to the laboratory. Any survivors were killed with chloroform vapour and each batch was crushed to a dark fluid in broth and several loopfuls plated on MacConkey's lactose-agar. Altogether 11 batches were examined but no Dysentery bacilli were found. If present in very small numbers they would be easily missed by this method as such a small proportion of the emulsion was examined. A bacillus resembling the mannite type of dysentery in many respects and described by Ledingham (1911) (Bac. A) was found in three batches of flies. It is differentiated by its acid production in adonite, marked alkalinity in litmus milk, and slight motility. Other organisms found were B. proteus, B. prodigiosus, and Morgan's No. 5 .

\section{Feeding experiments.}

F. B. Bowman (1910) recently recorded the spontaneous occurrence of Bacillary dysentery in monkeys in the Philippines. The origin of the infection could not be traced but $B$. Flexner was found in the lesions. In view of this and the marked susceptibility of monkeys for Morgan's Bacillus No. 1 of summer diarrhoea, several attempts were made to infect a healthy full-grown monkey (Macacus rhesus). No non-lactose fermenters were found in the faeces beforehand. 
1. 100 c.c. milk +100 c.c. of a 48 -hours broth culture of a freshly isolated sorbite-fermenting Dysentery bacillus were given on an empty stomach, about half of this quantity being ingested. Nothing resulted except slight constipation and the organism was not recovered from the stools three days later.

2. Four agar slopes of the same strain were given six days later mixed with milk and potato, followed again by apparent constipation.

3. Two weeks later a stomach tube was passed, 1 drachm of bicarbonate of soda dissolved in water administered to neutralise any acidity, followed by 200 c.c. of a 48-hours broth culture, again without any noticeable effect on the general health. After a week calomel was given and no non-lactose fermenters were found in the resulting stool.

4. After a month another sorbite-fermenting strain was given by method 3, after first passing the organism through the peritoneum of a guinea-pig. Result again negative.

5. In view of these failures the laboratory strain of B. Flexner was administered in the same way without success.

It was rather unfortunate that the same monkey had to be used for all these experiments, but there is no doubt but that this animal was able to withstand enormous doses of bacilli freshly isolated from cases of asylum dysentery. It is rather noteworthy also that on no occasion were the bacilli isolated from the stools which were always of a formed character.

\section{SUMMARY.}

(1) A number of Dysentery bacilli of the mannite-fermenting type have been isolated from an English asylum.

(2) These bacilli may be divided into two sub-groups, (a) those that do, and (b) those that do not (1) ferment sorbite and (2) form indol in peptone beef broth in six days.

(3) Several attempts to infect a monkey with sorbite-fermenting strains were not successful.

(4) No Dysentery bacilli were found in an examination of a considerable number of flies infesting the surroundings of chronic and acute cases of bacillary dysentery.

My thanks are due to $\mathrm{Dr} H$. de R. Morgan for kindly co-operation in part of this work, to Dr J. C. G. Ledingham for his valuable advice and assistance at all times, and to Dr W. F. Menzies for supplying the material for examination. 


\section{REFERENCES.}

Aveline, Boycott and MacDonald (1908). Bacillus dysenteriae of Flexner in relation to Asylum Dysentery. Journ. of Hygiene, viII. 309.

Bainbridge and DudField (1911). An outbreak of dysentery. Journ. of Hygiene, XI. 356.

Bowman, F. B. (1910). A note on the spontaneous occurrence of bacillary dysentery in monkeys. Philippine Journ. of Science, Manilla, 1910, B. v. 481.

Candler and Dean, G. (1911). A contribution to the study of institutional dysentery. Archiv of Neurology, v. 74.

Eyre, J. W. H. (1904). Asylum dysentery in relation to B. dysenteriae. Brit. Med. Journ. 1904, I. 1002.

LEDINGHAM, J. C. G. (1911). On the survival of specific micro-organisms in pupae and imagines of Musca domestica raised from experimentally infected larvae. Experiments with B. typhosus. Journ. of Hygiene, xI. 333.

MAcAlister, G. H. K. (1910). Dysentery carriers. Brit. Med. Journ. II. 1056.

Marshali, W. (1909). Case of acute sporadic dysentery in a child associated with the presence of B. dysenteriae (Flexner). Journ. Roy. Army Med. Corps, xIr. 556.

MacWeeney, E. J. (1905). Asylum dysentery. Brit. Med. Journ. I. 943.

- (1906). Asylum dysentery. Brit. Med. Journ. I. 1564.

Morgan, H. de R. (1906). Upon the bacteriology of summer diarrhoea of infunts. Brit. Med. Journ. I. 908.

- (1907). Upon the bacteriology of summer diarrhoea of infants. Brit. Med. Journ. II. 16.

- (1911). The differentiation of the mannite fermenting group of $B$. dysenteriae with special reference to strains isolated from various sources in this country. Journ. of Hygiene, xI. 1.

Morgan and Ledingham (1909). The bacteriology of summer diarrhoea. Proc. Royal Soc. of Medicine (Epid. Section), II. 133. 